DOI: $10.17747 /$ TEDS-2020-12-16

Anton B. Georgievsky ${ }^{1}$

Graduate School of Business

National Research University Higher School of Economics

Moscow, Russia

1520789@mail.ru

\title{
CREATING ECOSYSTEM VALUE PROPOSITION BASED ON SELLING SOLUTIONS IN THE DIGITAL ECONOMY
}

\begin{abstract}
The development of digital technologies and the ongoing coronavirus pandemic contribute to expanding the company's opportunities to provide a complete value proposition to the client. The purpose of this article is to determine groups of components of the value proposition based on selling solutions in the ecosystem and identify strategies that allow creating such a value proposition in the digital economy. The research method is based on the analysis of academic and consulting literature. As a result of the research, groups of components of the value proposition based on selling solutions in the ecosystem were formed, and strategies for the formation of the value proposition were identified. These results will help researchers build new models of the value proposition, and entrepreneurs form value propositions that fully satisfy customer needs.

Keywords - ecosystem; value proposition; components; strategies; coronavirus pandemic; consumer trends; solutions; selling solutions; digitalization; digital economy; ecosystem value proposition; customer needs
\end{abstract}

\section{RESEARCH QUESTION}

The digitalization of existing processes in the economy leads to an increase in the consumer's role in forming the value proposition. Traditional sales offer customers separate products or services, considering the customer needs rather narrowly. Companies understand that a great potential for business development in the digital economy lies in complete customer satisfaction. For this purpose, the company can use selling solutions. The development of digital technologies, in particular big data, the Internet of Things, and sensors, allows the company to know its customers much better and interact with them closer than ever. Often, the company alone is difficult to offer a complete solution to the client's problem. Therefore, the company forms an ecosystem in which a group of actors, including the client, creates a joint value proposition.

Although the concepts of selling solutions, value proposition, and ecosystem are quite popular, integrating these topics in one study is given very little attention in the academic literature. Among the key issues of a value proposition is the identification of its components and strategies for its formation. This article aims to determine groups of components of the value proposition based on selling solutions in the ecosystem and its formation strategies.

These findings will help companies create a competitive advantage and increase their profits. Researches will receive conceptual models to create new models of the ecosystem value proposition.

\section{LITERATURE REVIEW}

This work links three related concepts: selling solutions, value proposition, and ecosystem.

The concept of selling solutions has become especially popular in recent years due to the development of the service lens [1] that integrated the ideas of service-dominant logic [2] and the concept of jobs to be done [3]. The service lens focuses not on the resources of only one company, but the resource integration between different actors in the value co-creation process. The development of the service lens allowed the company to look at customer problems more broadly and pay more attention to interaction with clients. The shift to value cocreation implemented within the servicedominant logic has opened up the opportunity to analyze a value-in-use context that contains many previously unrevealed customer needs and potential sources of strategic advantage. 
Traditionally, the concept of a value proposition has been viewed in terms of product logic. The value proposition was unidirectional, and the value was built into the product by the manufacturer. A key goal of the value proposition was to reflect the product's advantages over the competitors. With the development of service-dominant logic, the value proposition began to focus on the interaction process of value creation. Modern value propositions go beyond the established supplierclient relationship and include many stakeholders or actors [4].

As the researchers note, ecosystems are a possible option for providing solutions [5]. They are characterized by a high degree of modularity and the need for coordination between participants. At the same time, this organizational form is distinguished by the absence of a full hierarchy control, which allows companies to be flexible when forming a value proposition [6]. Actors strive to find an optimal position in the ecosystem with a balance between the value generated for the ecosystem and the value created for the participant.

According to the structural perspective of the ecosystem [7], the value proposition determines ecosystem design [8] and required partners for the realization of the value proposition. It is essential to understand that the client is an ecosystem actor actively involved in value creation. Moreover, according to the service-dominant logic, the value is determined by the client [9]. It is important to note that the client's ability to co-create value increases with the opportunities provided by digital technologies [10].

Thus, accompanied by the development of the digital economy, the integration of these concepts is a necessary step to fully meet customer needs.

\section{THEORETICAL GROUNDING AND METHODOLOGY}

One of the most popular models describing value formation in the ecosystem is the Ecosystem Pie Model proposed by Talmar et al. [11]. This model serves as a response to the request for a structural approach to creating an ecosystem [12]. The model describes the structure of the ecosystem and considers the activities of key actors. The value proposition is the core element of the model. There are two main features of this model. First, it considers value both at the ecosystem level and at the company level. Secondly, it allows the visual depiction of the relationships between the actors involved in value co-creation. Despite the comprehensive approach to value formation, this model does not consider the components of the value proposition, strategies for its formation, and selling solutions as a particular case of value proposition creation.

A meta-analysis of academic and consulting works was used to determine groups of components of the value proposition based on selling solutions in the ecosystem. At the first stage, a list of academic papers containing value proposition models was formed based on scientific citation databases. After that, the components of the value proposition were selected from each model. As a result, a general list containing the components of the value proposition was obtained. Then the considered components were ranked by the number of mentions in the authors' works. The considered components and models of the value proposition were classified based on several approaches. Based on the study of the literature on selling solutions and ecosystems, the most suitable components for forming the value proposition based on selling solutions in the ecosystem were identified among the proposed list of components. The components were formed into several groups, which were considered to create the value proposition in the digital economy.

In order to determine strategies for forming the value proposition based on selling solutions in the ecosystem, an analysis of academic and consulting literature on the three topics of interest was used.

\section{EMPIRICAL ANALYSIS}

The study presents four groups of components of the ecosystem value proposition based on selling solutions. The groups are designed for using digital technologies at each stage of solution development. 
The first group includes components focused on the process of providing a solution to the client. Here, the client's convenience becomes the key task of the ecosystem. The components of this group are based on concepts such as customer journey and customer experience. Augmented reality and virtual reality blur the line between brick-and-mortar and digital and make interaction with the ecosystem more valuable. The ecosystem should provide the convenience of touchpoints and demonstrate the advantages of the solution compared to competitors. The ecosystem can offer its customers omnichannel using a well-developed infrastructure of actors. Moreover, drones and robots are capable of enhancing fulfilment efficiency and speed up delivery.

The second group is aimed at achieving the client's goal. Customers, especially in B2B markets, can monitor the provided solution very carefully. Various sensors of the Internet of Things provide lots of opportunities for this purpose. At the same time, the effectiveness of the solution provided for the client's problem is a necessary attribute of the solution in B2C markets. Clients do not want to see the solution itself, but the result that they get from using it. Only in this case, the provided solution will make sense. Often, the client does not even own the property right, but uses the solution by subscription or pays for the time of use. The SaaS (Software as a Service) model can serve as a means of providing such solutions. It is worth noting that a payment-forresults model is widely used in selling solutions, ensuring the solution's effectiveness for customers.

The group of communication components gets unprecedented opportunities for development due to the spread of digital technologies. Companies are constantly present in the clients' lives, communicating with them in social networks and messengers. This group of components correlates with the development of the relational paradigm in marketing, which focuses on the interaction between the company and the client, joint value creation, and orientation on building long-term relationships. The constant use of the smartphone by clients creates opportunities for ensuring regular contact between the company and the client through applications and technologies. Using beacon technology and GPS data helps clients stay connected. It is important to note that despite the digitalization of most processes, personal communication between customers and employees is still critical.

The fourth group of components allows the company to determine how widely the company considers the client's problem and offer the client a personalized solution. It is important to emphasize that it is the client who determines what is valuable. Personalized value is based on the client's deep knowledge, the analysis of big data, and the flexible configuration of the processes that form the solution.

The crucial task for solutions is to take a broad view of the client's needs. This fact opens up opportunities to offer the client various related offers. It is especially promising for building longterm relationships with the client. In this case, the solution to all problems within a specific need for the client will be associated with a specific ecosystem. The clients leave much information about themselves by interacting with the company through the personal communication, app, site, community, and loyalty programs. Based on big data analysis, artificial intelligence can predict what services a customer may need and when. Fig. 1 depicts the proposed groups of components.

Fig. 1. Groups of components of the ecosystem value proposition based on selling solutions.

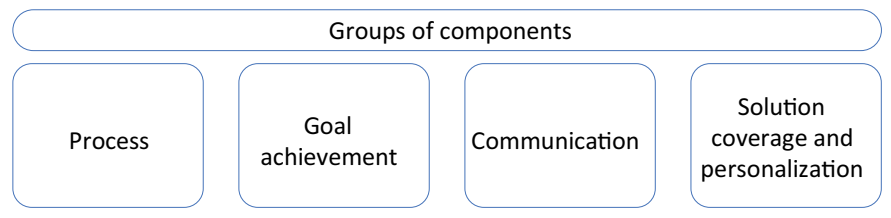


The study identifies strategies for creating the value proposition based on selling solutions in the ecosystem. The strategies vary according to the extent of their coverage.

The company can view the market as broadly as possible and offer various loosely coupled solutions to different clients. In these conditions, it is critical to have a digital platform that allows the company to combine all solutions in one place and make them convenient for the client. Most often, this strategy is used by companies operating in the information technology and banking sectors. It requires significant resources and a large client base.

Another option is to meet the needs of a specific group of customers. In this case, the needs become linked, and the company provides the customer with many related solutions. A significant role here is played by analyzing customer data to better understand customers and using artificial intelligence to provide solutions that may be of interest to them from several related areas covered by the ecosystem. In addition to the main offer of goods and services, the company may provide education services, personal recommendations, and other solutions for each day.

The most concentrated strategy is to focus on the complete satisfaction of one customer need. The strategy requires a high degree of coordination of all ecosystem participants, which involves using digital technologies to constantly exchange data on the progress of the solution. The ecosystem can use cloudbased services that collect and analyze huge volumes of data. It reduces costs and makes the ecosystem more flexible. As a rule, this strategy is implemented by small ecosystems that can perform all tasks within a specific need better than other market players.

The company chooses a strategy based on the capabilities of the ecosystem participants and the potential market (Fig. 2).

Fig. 2. Strategies for creating the ecosystem value proposition based on selling solutions.

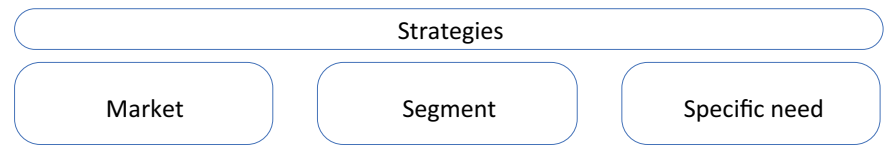

The proposed groups of components and strategies for forming the ecosystem value proposition based on selling solutions help practitioners and researchers create value propositions and their models that will allow companies to be profitable in the digital economy.

\section{REFERENCES}

[1] L. Bettencourt, R. Lusch, and S. Vargo, "A service lens on value creation: marketing's role in achieving strategic advantage," California Management Review, vol. 57, pp. 44-66, 2014. doi: $10.1525 / \mathrm{cmr} .2014 .57 .1 .44$

[2] S.L. Vargo and R. Lusch, "Evolving to a new dominant logic for marketing," Journal of Marketing, vol. 68, pp. 1-17, 2004. doi: 10.1509/jmkg.68.1.1.24036

[3] T. Ulwick, "What is jobs-to-be-done?," URL: https://jobs-to-bedone.com/ what-is-jobs-to-be-done-fea59c8e39eb

[4] P. Frow et al., "Value propositions: a service ecosystems perspective," Marketing Theory, vol. 23, pp. 1-25, 2014. doi: 10.1177/1470593114534346

[5] J. Stonig and G. Müller-Stewens, "Navigating the challenges of ecosystem emergence: a multi-level review of leader and complementor strategies," Die Unternehmung, vol. 73, no. 4, pp. 288-307, 2019. doi: 10.5771/0042-059X-2019-4-288

[6] M. Jacobides, C. Cennamo, and A. Gawer, "Towards a theory of ecosystems," Strategic Management Journal, vol. 39, pp. 2255-2276, 2018. doi: 10.1002/smj.2904 
[7] R. Adner, "Ecosystem as structure: an actionable construct for strategy," Journal of Management, vol. 43, no. 1, pp. 39-58, 2017. doi: 10.1177/0149206316678451

[8] U. Pidun, M. Reeves, and M. Schüssler, "How do you "design" a business ecosystem?," URL: https://www.bcg.com/publications/2020/how-do-you-design-a-businessecosystem

[9] S.L. Vargo and R. Lusch, "Service-dominant logic: continuing the evolution," Journal of the Academy of marketing Science, vol. 36, pp. 1-10, 2008. doi: 10.1007/s11747-007-0069-6

[10] E. Marcon et al., "Barriers for the digitalization of servitization," Procedia CIRP, vol. 83, pp. 254-259, 2019. doi: 10.1016/j.procir.2019.03.129

[11] M. Talmar, B. Walrave, K. Podoynitsyna, J. Holmström, and G. Romme, "Mapping, analyzing and designing innovation ecosystems: The Ecosystem Pie Model," Long Range Planning, vol. 53, no. 4, 101872, 2020. doi: 10.1016/j.lrp.2018.09.002

[12] D. Hannah and K. Eisenhardt, "How firms navigate cooperation and competition in nascent ecosystems," Strategic Management Journal, vol. 39, pp. 3163-3192, 2018. doi: $10.1002 / \mathrm{smj} .2750$ 